\title{
Acidentes de trabalho com agentes comunitários de saúde
}

\author{
Occupational accidents involving community health agents \\ Accidentes de trabajo con agentes comunitarios de salud
}

Mirian Cristina dos Santos Almeida'; Patricia Campos Pavan Baptistal"; Arlete Silval".

\begin{abstract}
RESUMO
Objetivo: analisar os acidentes de trabalho ocorridos com agentes comunitários de saúde (ACS) do município de Caraguatatuba/ SP/Brasil. Método: pesquisa descritiva, transversal, com abordagem quantitativa. Após anuência do Comitê de Ética e Pesquisa da Universidade Guarulhos (Parecer no 723/11), os dados foram coletados com 137 ACS, em 2012, por meio de questionário e entrevista. Resultados: constatou-se que 59(43,07\%) ACS sofreram 80 acidentes de trabalho, sendo os mais frequentes: traumatismo do ciclista (ACS) em acidente de transporte, mordedura provocada por cão e quedas; $64(80 \%)$ dos acidentes foram típicos, $13(16,25 \%)$ de trajeto e $3(3,75 \%)$ doença do trabalho. Apenas 31(38,75\%) acidentes foram notificados por meio da Comunicação de Acidentes de Trabalho e 16(20\%) ocasionaram afastamento dos ACS das atividades laborais. Conclusão: os resultados alertam para a importância da promoção de medidas preventivas e interventivas no exercício do trabalho do ACS.
\end{abstract}

Palavras-chave: Agentes comunitários de saúde; acidentes de trabalho; notificação de acidentes de trabalho; saúde do trabalhador.

\section{ABSTRACT}

Objective: to analyze occurrence of occupational accidents in community health agents (CHAs) in the municipality of Caraguatatuba, São Paulo, Brazil. Method: in this quantitative, descriptive, cross-sectional study, approved by the Research Ethics Committee of Guarulhos University (No. 723/11), data were collected from 137 CHAs, in 2012, using a questionnaire and interview. Results: 59(43.07\%) CHAs were found to have had 80 occupational accidents, the most frequent being CHA cyclist injured in traffic accident, by dog bite or by fall; $64(80.00 \%)$ were typical to the profession, $13(16.25 \%)$ were travel accidents and $3(3.75 \%)$ were occupational disease. Only $31(38.75 \%)$ of the accidents were reported by Occupational Accident Notification, and $16(20.00 \%)$ entailed absence from work. Conclusion: these results alert to the importance of promoting preventive and intervention measures in CHA working conditions. Keywords: Community health workers; accidents, occupational; occupational accidents registry; occupational health.

\section{RESUMEN}

Objetivo: analizar los accidentes de trabajo ocurridos con agentes comunitarios de salud (ACS) del municipio de Caraguatatuba/SP/ Brasil. Método: estudio descriptivo, transversal, con enfoque cuantitativo. Después de la aprobación del Comité de Ética en Investigación de la Universidad de Guarulhos (Dictamen № 723/11), los datos fueron colectados junto a 137 ACS, en 2012, por medio de cuestionario y entrevista. Resultados: se encontró que 59(43,07\%) ACS sufrieron 80 accidentes de trabajo, siendo los más frecuentes: traumatismo de ciclista (ACS) en accidente de transporte, mordedura provocada por perro y caídas; 64(80,00\%) de los accidentes fueron típicos, $13(16,25 \%)$ de desplazamiento y $3(3,75 \%)$ enfermedad del trabajo. Apenas $31(38,75 \%)$ de los accidentes fueron notificados por medio de la Declaración de Accidentes de Trabajo y 16(20,00\%) necesitaron de licencia de las actividades laborales. Conclusión: los resultados alertan sobre la importancia de la promoción de medidas preventivas e interventoras en el ejercicio de la labor del ACS. Palabras clave: Agentes comunitarios de salud; accidentes de trabajo; notificación de accidentes del trabajo; salud laboral.

\section{INTRODUÇÃO}

Os acidentes e adoecimento no trabalho em trabaIhadores da saúde são alvos de preocupação de diversos pesquisadores evidenciando uma problemática séria no contexto nacional e internacional ${ }^{1-4}$. No entanto, ainda existe escassez de estudos acerca dos acidentes com trabalhadores da atenção básica, primeiro nível de contato da população com o serviço de saúde, atuando principalmente na promoção da saúde e prevenção de agravos² .

Entre os diversos profissionais da atenção básica à saúde, o agente comunitário de saúde (ACS) foi inserido em diversos países, para populações específicas, após a Conferência Internacional de Cuidados Primários à Saúde em 1978, na antiga União Soviética, que defendia saúde para todos ${ }^{5}$. Atualmente, este profissional está presente em programas de saúde pública de países como Etiópia, Moçambique, Uganda, Bangladesh, Paquistão, Tailândia, Haiti, entre outros ${ }^{6}$. No Brasil o ACS teve seu trabalho institucionalizado, no contexto da Saúde Pública Nacional, na década de 90, com a criação do Programa Agente Comunitário de Saúde

'Enfermeira. Mestre em Enfermagem. Doutoranda em Ciências: Universidade de São Paulo, Escola de Enfermagem. São Paulo, Brasil. E-mail: miriandresp@ @otmail.com. "Enfermeira. Doutora. Professora Associada: Universidade de São Paulo, Escola de Enfermagem, Departamento de Orientação Profissional. São Paulo, Brasil. E-mail: pavanpati@usp.br.

'"Enfermeira. Doutora. Professora Aposentada: Universidade de São Paulo, Escola de Enfermagem. São Paulo, Brasil. E-mail: arlsilva@uol.com.br 
(PACS) e posteriormente o Programa Saúde da Família (PSF), hoje denominado Estratégia Saúde da Família (ESF). O seu trabalho se caracteriza pela realização de visitas domiciliares a todas as famílias de sua microárea de abrangência, desenvolvendo ações individuais ou coletivas de prevenção e promoção à saúde, sendo este importante elo entre a população e os demais membros da ESF. Segundo o Ministério da Saúde (MS), em 1998, havia 59.066 ACS em todo o Brasil. Com a expansão da ESF, o número de ACS cresceu consideravelmente, chegando a 272.718 em agosto de 2016, para atender a mais de 129 milhões de brasileiros ${ }^{7}$.

O interesse para a realização deste estudo decorreu da vivência de uma das autoras como enfermeira da ESF e da preocupação com os acidentes de trabalho (AT) sofridos por ACS com os quais trabalhava. Soma-se a isso o conhecimento restrito sobre a ocorrência de AT com os ACS, o que dificulta a organização de programas de prevenção e de promoção da saúde desses trabalhadores que se tornaram de fundamental importância na atenção básica à saúde, em âmbito nacional. Assim, esta pesquisa teve por objetivo analisar os AT ocorridos com ACS do município de Caraguatatuba-SP.

\section{REVISÃo DE LITERATURA}

A saúde do trabalhador envolve um conjunto de ações que tem o objetivo de proporcionar promoção, proteção, recuperação e reabilitação da saúde dos trabaIhadores submetidos aos riscos e agravos advindos das condições de trabalho, abrangendo entre outros aspectos a assistência ao trabalhador vítima de $\mathrm{AT}^{8}$. Para tanto, no Brasil, a Política Nacional de Saúde do Trabalhador é organizada de modo que os princípios e diretrizes do Sistema Único de Saúde (SUS) sejam observados em todas as esferas do governo para o "desenvolvimento da atenção integral à saúde do trabalhador, com ênfase na vigilância, visando à promoção e à proteção da saúde dos trabalhadores e à redução da morbimortalidade decorrente dos modelos de desenvolvimento e dos processos produtivos"9:46.

Neste contexto, destacam-se os AT classificados em típicos: decorrentes do exercício da atividade profissional; de trajeto: ocorridos durante o percurso entre a residência e o local de trabalho e vice-versa; e doença do trabalho: produzidas pelo exercício do trabalho peculiar ao ramo de atividade constante do Regulamento da Previdência Social do Brasil ${ }^{10}$. Todos os AT ocorridos com trabalhadores contratados segundo o regime da Consolidação das Leis do TrabaIho (CLT) devem ser notificados pela empresa, por meio de Comunicação de Acidente de Trabalho (CAT), à Previdência Social, independente do tipo de acidente e da necessidade de afastamento ou não das atividades trabalhistas ${ }^{11}$.

\section{Metodologia}

Trata-se de um estudo descritivo, de campo, transversal, com abordagem quantitativa. A coleta de dados foi realizada em janeiro de 2012, nas unidades básicas de saúde (UBS) do município de Caraguatatuba/
$\mathrm{SP} /$ Brasil, que abrigam $22 \mathrm{ESF}$, com um quadro total de 166 ACS, contratados no regime da CLT.

A amostra foi constituída de 137 ACS. Dos 29 ACS que não participaram do estudo, quatro estavam de licença médica, 16 de férias, dois se recusaram a participar do estudo e sete foram demitidos no período da coleta de dados.

Os dados foram coletados por uma das pesquisadoras, após autorização institucional e aprovação pelo Comitê de Ética em Pesquisa da Universidade Guarulhos (Parecer no 723/11). Durante reunião de equipe da ESF, os ACS foram convidados a participar da pesquisa, recebendo todas as informações pertinentes e, aqueles que concordaram, assinaram o Termo de Consentimento Livre e Esclarecido. Seguiu-se a aplicação de um questionário contendo dados sociodemográficos e de trabalho, e logo após os ACS foram entrevistados, em sala reservada, sobre a ocorrência e descrição do AT, a realização de notificação e a necessidade de internação e/ou afastamento. Os AT foram agrupados segundo a Classificação Estatística Internacional de Doenças e Problemas Relacionados à Saúde (CID 10) e foi realizada análise estatística descritiva simples dos dados.

\section{RESULTADOS}

Dos 137 ACS participantes do estudo, 129 (94,16\%) são do sexo feminino, com idade entre 19 e 62 anos (média 34,79 anos; $d p 9,96)$ e $83(60,58 \%)$ informaram união conjugal estável.

O tempo de serviço como ACS variou de 25 dias a 11 anos (média 3,17anos; dp2,88), com carga horária semanal de trabalho de 40 horas. Para exercer o trabalho, principalmente as visitas domiciliares, 104 (75,91\%) ACS referiram utilizar a bicicleta como meio de transporte; $16(11,68 \%)$ realizavam o trabalho a pé; $14(10,22 \%)$ utilizavam bicicleta ou se locomoviam a pé; $2(1,46 \%)$ utilizavam moto e $1(0,73 \%)$ utilizava bicicleta ou moto.

Dentre os 137 ACS entrevistados, 59 (43,07\%) relataram ter sofrido AT durante a sua carreira profissional: 44 (74,58\%) referiram um AT, 7 (11,86\%) - dois AT, 6 (10,17\%) - três AT, 1 (1,69 \%) - quatro AT e 1 (1,69\%) não soube quantificar.

Os 80 (100\%) AT referidos pelos 59 ACS foram agrupados segundo a Classificação Estatística Internacional de Doenças e Problemas Relacionados à Saúde - CID 10 , sendo mais prevalente o grupo causas externas de morbidade e de mortalidade (V01-Y98), conforme dados apresentados na Tabela 1.

A maior parte dos AT ocorreu com ciclistas traumatizados em acidente de transporte, seguido por mordedura ou golpe provocado por cão, quedas e exposição a forças mecânicas inanimadas. Ver Trabalho 1.

Quanto ao tipo de AT, 64(80\%) foram típicos, $13(16,25 \%)$ de trajeto e $3(3,75 \%)$ doença do trabalho.

Segundo o local de ocorrência dos AT típicos e de trajeto, 59(76,62\%) aconteceram em via pública, 
TABELA 1: Distribuição dos acidentes de trabalho relatados pelos agentes comunitários de saúde, segundo a Classificação Estatística Internacional de Doenças e Problemas Relacionados à Saúde (CID 10). Caraguatatuba, SP, 2012.

\begin{tabular}{|c|c|c|}
\hline Acidentes de Trabalho & f & $\%$ \\
\hline F40-F48 Transtornos neuróticos, transtomos relacionados com o stress e transtomos somatoformes & 1 & 1,25 \\
\hline F43 Reações ao stress grave e transtornos de a daptação & 1 & 1,25 \\
\hline H10-H13 Transtornos da conjuntiva & 2 & 2,50 \\
\hline H10 Conjuntivite & 2 & 2,50 \\
\hline S90-S99 Traumatismos do tornozelo e do pé & 1 & 1,25 \\
\hline S91.2 Ferimento do(s) artelho(s) com lesão da unha & 1 & 1,25 \\
\hline V01-V09 Pedestre traumatizado em um acidente de transporte & 1 & 1,25 \\
\hline V03 Pedestre traumatiza do em colisão com um a utomóvel [ca rro], pick up ou caminhonete & 1 & 1,25 \\
\hline V10-V19 Ciclista traumatizado em um acidente de transporte & 43 & 53,75 \\
\hline V10 Ciclista traumatizado em colisão com um pedestre ou um a nimal & 3 & 3,75 \\
\hline V11 Ciclista traumatizado em colisão comoutro veículoa pedal & 4 & 5,00 \\
\hline V12 Ciclista traumatizado em colisão com um veículo a motor de duas ou três rodas & 3 & 3,75 \\
\hline V13 Ciclista traumatizado em colisão com um automóvel, pick up ou caminhonete & 4 & 5,00 \\
\hline V14 Ciclista traumatizado em colisão com um veículo de transporte pesa do ou um ônibus & 1 & 1,25 \\
\hline V18 Ciclista traumatizado em um a cidente de transporte sem colisão & 28 & 35,00 \\
\hline V20-V29 Motociclista traumatizado em um acidente de transporte & 2 & 2,50 \\
\hline V28 Motociclista tra umatizado em um a cidente de transporte sem colisão & 2 & 2,50 \\
\hline W00-W19 Quedas & 12 & 15,00 \\
\hline W01 Queda no mesmo nível por escorregão, tropeção ou passos em falsos [traspés] & 9 & 11,25 \\
\hline W10 Queda em ou de escadas ou degraus & 2 & 2,50 \\
\hline W17 Outras quedas de um nível a outro & 1 & 1,25 \\
\hline W20-W49 Exposição a forças mecânicas inanimadas & 5 & 6,25 \\
\hline W45 Penetração de corpo ou objeto estranho através da pele & 1 & 1,25 \\
\hline W46 Contato com agulha hipodérmica & 1 & 1,25 \\
\hline W49 Exposiçãoa outras forças mecânicas inanimadas e às não especifica das & 3 & 3,75 \\
\hline W50-W64 Exposição a forças mecânicas animadas & 13 & 16,25 \\
\hline W54 Mordedura ou golpe provocado por cão & 13 & 16,25 \\
\hline Total & 80 & 100,00 \\
\hline
\end{tabular}

seguido de $12(15,58 \%)$ no quintal da residência do paciente, $3(3,90 \%)$ na UBS, $2(2,60 \%)$ na escada do prédio do paciente e $1(1,30 \%)$ no posto de gasolina, quando o ACS estava calibrando o pneu de sua bicicleta.

Dos 80 AT, 49(61,25\%) não foram notificados oficialmente por meio da CAT. Quando indagados sobre o motivo da não notificação, relataram que por vezes comunicaram o acidente ao enfermeiro, médico ou auxiliar de enfermagem da ESF e que, frequentemente, não o notificavam por não ter havido lesões graves.

$\mathrm{O}$ agente causador dos AT mais apontado pelos ACS foi representado por irregularidades na via pública, cão e bicicleta/ ciclista, conforme dados apresentados na Tabela 2. Também foi apontado(outros) piso escorregadio na UBS, vaso sanitário quebrado, lata, espinho, blusa do agasalho, caminhão, pedestre, guarda chuva, entulhos, telha que cobria fossa desativada, tamanco de outro ACS, lanceta de glicemia capilar e pressão no trabalho/ desentendimento em casa.

As partes do corpo afetadas pelos AT foram: 50(51,03\%) - membros inferiores, seguido de 26(26,53\%) - membros superiores, 8(8,16\%) - tórax, 7(7,14\%) - região pélvica, 6(6,12\%) - cabeça e 1(1,02\%) - abdome, totalizando 98 , visto que dos 80 AT ocorridos, alguns afetaram mais de uma parte do corpo.
Das 97 lesões identificadas, as superficiais de partes moles foram as mais frequentes com $46(47,43 \%)$ ocorrências, seguidas de 38(39,18\%) - contusão/hematoma/edema. Também foi relatado 5(5,15\%) - luxação/ entorse devido a quedas e acidentes de transporte; 2(2,06\%) - lesões traumáticas incisas pela manipulação de entulhos (vaso sanitário quebrado e lata) no quintal da casa do paciente, durante vistoria de prevenção a dengue; 2(2,06\%) lesões traumáticas perfurantes

TABELA 2: Distribuição dos acidentes de trabalho ocorridos com agentes comunitários de saúde, segundo o agente causador. Caraguatatuba, SP, 2012.

\begin{tabular}{lcc}
\hline Agente causador & $\mathbf{f}$ & $\mathbf{\%}$ \\
\hline Irregularidades em via pública (barro, & & \\
limo, buraco, areia, pedregulhos) & 21 & 26,25 \\
Cão & 16 & 20,00 \\
Bicicleta/Ciclista & 14 & 17,50 \\
Automóvel & 5 & 6,25 \\
Moto/Motociclista & 4 & 5,00 \\
Des equilíbrio do próprio corpo & 3 & 3,75 \\
Microorganismo & 2 & 2,50 \\
Esca da ema mbiente escuro & 2 & 2,50 \\
Outros & 13 & 16,25 \\
Total & $\mathbf{8 0}$ & $\mathbf{1 0 0 , 0 0}$ \\
\hline
\end{tabular}


decorrentes de acidente com lanceta para teste de glicemia capilar e por perfuração de membro inferior com espinho durante visita domiciliar; $1(1,03 \%)$ lesão de parte mole profunda por mordida de cão na região glútea; $1(1,03 \%)$ fratura de dedo da mão devido à colisão entre ACS ciclista e um carro; uma $(1,03 \%)$ concussão por colisão do ACS ciclista com um pedestre e; $1(1,03 \%)$ exérese de unha ocasionada por pisada acidental com tamanco no segundo pododáctilo esquerdo.

Vale registrar que $12(20 \%)$ AT resultaram em afastamento das atividades laborais, por um período mínimo de um dia e máximo de 35 dias (média 8,93; $d p 10,15$ dias), sendo mais frequente o período de 1 a 4 dias, com 7(43,75\%) ocorrências.

\section{DISCUSSÃo}

Estudo realizado em Sidrolândia/MS/Brasil constatou que $26,82 \%$ dos ACS foram vítimas de AT durante o exercício de suas atividades, percentil inferior ao observado no presente estudo, em que quase metade já sofreu algum tipo de $\mathrm{AT}^{12}$.

A maior parte dos AT estava relacionada a acidentes de transporte envolvendo bicicleta, por ser este o meio de transporte mais utilizado pelos ACS de Caraguatatuba/SP/Brasil, seja para desenvolver suas atividades de visita domiciliar na microárea de atenção ou para locomoção da própria residência ao trabalho e vice-versa; $35 \%$ destes acidentes ocorreram sem colisão quando a bicicleta derrapou, parou bruscamente por algum objeto ter enroscado na roda, e por falta de manutenção (problema no freio, guidão da bicicleta que se soltou), entre outras causas.

As mordeduras ou golpes provocados por cães, segunda causa de AT, ocorreram em via pública e também no quintal das residências dos pacientes, e muitas vezes na presença do próprio dono do animal. Sabe-se que as mordeduras provocadas por cães são altamente infectantes, podendo transmitir raiva e outras doenças decorrentes dos microrganismos presentes na saliva do animal, no ambiente e na pele da vítima, sendo necessárias medidas profiláticas de prevenção de raiva humana, tétano e tratamento antimicrobiano conforme a avaliação individual dos $\operatorname{casos}^{13}$.

As quedas, terceira causa de AT, envolveram queda da própria altura por escorregão ou tropeção; queda de degraus da escada de um edifício durante visita domiciliar, em ambiente escuro; e queda de um nível a outro, quando a ACS caiu dentro de uma fossa desativada, no quintal da residência de um cliente.

Em outra pesquisa com ACS, as quedas foram as mais prevalentes $(54,54 \%)$, seguida por mordida de cachorro, picadas de insetos e acidente com arame farpado $^{12}$. Estudos realizados no Canadá com trabalhadores de saúde identificaram que o risco de sofrer quedas foi significativamente maior em trabalhadores de serviços de suporte, ACS, mulheres e pessoas com mais de 60 anos. As atividades que mais contribuíram para as quedas foram andar ou correr e empurrar ou pegar objetos e os principais fatores que levaram as quedas foram o tipo de piso (escorregadios, superfícies irregulares e tapetes) e trabalhar em ambiente ao ar livre ${ }^{14}$.

A exposição a forças mecânicas inanimadas, quarta causa de AT nos ACS, ocorreu por penetração de corpo ou objeto estranho através da pele, quando um espinho perfurou o pé do ACS, que calçava sandália, durante realização de visita domiciliar; perfuração com agulha hipodérmica, quando uma ACS estava assinando a folha de registro do ponto em uma mesa onde a auxiliar de enfermagem realizava teste de glicemia capilar, a agulha caiu no chão e a ACS, ao pegá-la, perfurou o dedo da mão; corte com lata e vaso sanitário quebrado, durante realização de vistoria de prevenção de dengue em quintal de residência; e o aro da bicicleta que se rompeu quando a ACS calibrava o pneu contundindo o membro superior. $\mathrm{O}$ acidente que provocou ferimento de um dos artelhos com lesão de unha foi causado pelo ACS que calçava tamanco de madeira e pisou acidentalmente no pé de outro ACS que estava de sandália, extraindo instantaneamente a unha do segundo pododáctilo esquerdo.

Estudos sobre AT com ACS ainda são escassos, porém pesquisas recentes, englobando todos os profissionais da saúde, apontam o ACS como vítima de acidentes com material biológico/perfuro cortante ${ }^{15,16}$. Estes dados remetem à importância da profilaxia contra Hepatite B e tétano para o ACS.

Foram apontadas apenas três ocorrências de doenças relacionadas ao trabalho: duas por conjuntivite, adquirida no trabalho durante um surto de conjuntivite na população assistida e uma por stress, talvez por desconhecimento sobre os tipos de AT. O baixo número de doenças relacionadas ao trabalho também foi identificado em pesquisas realizadas com profissionais da área da saúde e nas estatísticas de AT nacionais, cujos registros apontam a predominância de acidentes típicos, seguidos dos de trajeto ${ }^{10,17,18}$.

A literatura evidencia alta demanda psicológica no trabalho do ACS. Este, como elo entre a comunidade e o serviço de saúde, convive com problemas biológicos e sociais dos pacientes, enfrentando sentimentos de impotência e fragilidade, além da cobrança da comunidade pela baixa resolutividade, o que pode resultar em estresse crônico e consequentemente, altos níveis de burnout ${ }^{19-23}$.

A falta da notificação dos AT, mencionada na maioria dos casos, além de ser justificada pelos ACS pela baixa gravidade dos acidentes, pode estar relacionada ao fato de o registro da notificação ser centralizado junto ao setor administrativo da empresa, gestor da ESF no (local do presente estudo). Ainda há a burocracia exigida no preenchimento da CAT. Ao sofrer um AT, o ACS deve observa um protocolo - passar por uma consulta 
médica (na própria UBS ou outro serviço de saúde), onde deve ser emitido um atestado médico relatando a data, hora, circunstância do acidente e código da CID10. Após, deve comparecer ao setor administrativo da empresa, onde será realizada a CAT e outras decisões se necessárias, como o agendamento de consulta com médico do trabalho para perícia. Quando os acidentes são leves, sem lesões físicas ou até mesmo com lesões simples como escoriações e hematomas, os profissionais julgam, erroneamente, não ser necessário atendimento médico, que é exigido para realização de uma CAT e, além disto, reclamam de ter que se deslocar do bairro onde residem e trabalham até o setor administrativo da empresa, o que demanda tempo.

Em outro estudo com ACS, nenhum AT ocorrido foi notificado ${ }^{12}$. A subnotificação dos AT não é um problema recente e também ocorre com outros profissionais, sendo justificada pela irrelevância do dano, a frequência com que ocorre, o desconhecimento do protocolo de atendimento para AT, a burocracia para se fazer a CAT, a sobrecarga de trabalho e a displicência ${ }^{24,25}$.

É possível que as informações sobre a importância e a obrigatoriedade da notificação, independente da gravidade do AT e da descentralização das notificações para as UBS e demais serviços de saúde, possam minimizar a subnotificação.

No presente estudo, nenhuma doença do trabaIho foi notificada. De maneira geral os AT típicos e de trajeto são mais

facilmente notificados comparados às doenças ocupacionais, as quais requerem uma avaliação e comparação do nexo causal para serem reconhecidas como tal, ocasionando a subnotificação dos dados de adoecimento dos trabalhadores $26: 288$.

As irregularidades nas vias públicas como buracos, barro, limo, areia e pedregulhos, são causadores da maior parte dos AT com os ACS e estão relacionadas às quedas da própria altura, escorregões, tropeções, queda de bicicleta ou moto.

Os cães também são importantes causadores de acidentes, sejam por mordeduras ou por entrar na frente de bicicleta ou moto, resultando em quedas.

As áreas públicas com ausência de pavimentação, úmidas e escorregadias, e cães soltos, constituem parte dos riscos presentes no trabalho desses trabalhadores ${ }^{27}$.

As bicicletas ou ciclistas foram o terceiro agente causador mais relatado, lembrando que este é o principal meio de transporte utilizado para realização do trabalho do ACS em Caraguatatuba/SP/Brasil.

Pesquisa realizada com ciclistas, trabalhadores de Pelotas/RS/Brasil, verificou que entre os 293 entrevistados, 5,5\% se acidentaram no último ano, sendo na maioria acidentes leves (arranhão ou escoriação), sem necessidade de afastamento do trabalho; $15 \%$ das bicicletas examinadas estavam sem freios, e apenas $0,3 \%$ apresentavam todos os equipamentos de segurança exigidos pelo Código de Trânsito Brasileiro, quais sejam, campainha, sinalização noturna dianteira, traseira, lateral e nos pedais e espelho retrovisor do lado esquerdo, não sendo obrigatório o uso de capacete ${ }^{28}$.

Outro estudo, realizado em Ontário-Canadá, utilizou dados de análise legista de 129 mortes de ciclistas, com idade entre 10 e 83 anos, e verificou que andar de bicicleta sem capacete está associado a um maior risco de morte por lesão na cabeça ${ }^{29}$. É evidente a importância da realização da manutenção rotineira das bicicletas, bem como o seguimento das normas de trânsito, a construção de ciclovias/ciclofaixas e a utilização de capacete.

Os agentes causadores de acidentes no ACS são peculiares ao seu processo de trabalho, envolvendo na maioria das vezes o ambiente e os instrumentos utilizados para o exercício do trabalho, o que exige alto grau de atenção durante a sua atividade laboral. Ainda é preciso ressaltar a relevância dos equipamentos de proteção individual (EPI) que previnem acidentes.

Quanto à parte do corpo afetada, as mais frequentes foram os membros inferiores, seguido dos superiores, causados principalmente pelos acidentes de transporte em bicicleta e pelas mordeduras provocadas por cães. A maior parte das lesões incidiu em região pélvica, abdominal, torácica e cabeça e decorreram de acidentes de trânsito e quedas.

Ao comparar os ACS deste estudo com os carteiros, que realizam o seu trabalho a pé, de bicicleta ou moto, de residência em residência, verifica-se que as partes do corpo mais atingidas, nos AT, são semelhantes entre essas categorias dos carteiros que referiram mordeduras por cães, mais da metade sofreram lesões nas mãos ou pés e nas pernas ${ }^{30}$.

A maioria dos AT com ACS resultou em lesões superficiais de partes moles (escoriações e mordedura superficial de cão $47,43 \%$ ) e contusão/hematoma/ edema $(39,18 \%)$. Estes resultados denotam a importância do uso de equipamento de proteção individual (EPI) como calças compridas com tecido grosso do tipo jeans, para proteção dos membros inferiores; por ser uma cidade litorânea, com hábitos de vida peculiares, o uniforme dos ACS de Caraguatatuba/SP/Brasil é composto de camiseta de manga curta ou colete e bermuda de tecido leve, o que não contribui para a prevenção ou minimização de lesões, em caso de acidentes.

O afastamento do trabalho não foi necessário para a maior parte dos ACS acidentados, dados similares à pesquisa realizada com profissionais de enfermagem, em que $88,15 \%$ dos trabalhadores não necessitaram desse benefício ${ }^{17}$.

Nenhum dos ACS precisou de internação devido ao AT; alguns foram atendidos no Pronto Socorro do município e, após o atendimento e algumas horas em observação, foram dispensados.

O período de afastamento do trabalho teve a média de 8,93 dias, e a somatória foi de 143 dias, equivalente a 4 meses e 23 dias. Isto pode trazer consequências 
não só para os trabalhadores vítimas dos acidentes, como para os usuários do serviço de saúde e aos demais companheiros de trabalho, que ficam sobrecarregados com as tarefas daqueles que faltaram. Para cada dia de absenteísmo, cerca de 10 a 12 famílias deixam de receber atendimento, o que reforça a necessidade de se investir na prevenção de AT, já que estes não prejudicam somente o trabalhador, mas equipe assistencial e a comunidade em geral.

\section{CONCLUSÃO}

A análise dos AT ocorridos com ACS alerta para a necessidade de políticas públicas de segurança no trabalho, sendo imprescindível a adoção de estratégias que contribuam com a prevenção de acidentes e promoção da saúde desses trabalhadores.

Sugere-se que medidas de segurança, como profilaxia contra tétano e Hepatite B e utilização de EPI- como calça comprida de tecido grosso do tipo jeans, sapato fechado e (capacete para os que utilizam a bicicleta como transporte) - devam ser adotadas e controladas regularmente pela instituição empregadora.

Também se faz necessário que os ACS sejam orientados sobre os AT mais frequentes a sua categoria profissional, a notificação dos mesmos, importância do uso adequado dos EPI, medidas estas de extrema importância para a prevenção dos acidentes e formulação de políticas pública de promoção e proteção à saúde desses trabalhadores.

Como limitação deste estudo, deve-se considerar que a alta proporção de AT envolvendo a bicicleta pode estar relacionada às características do campo de pesquisa, uma cidade litorânea onde a bicicleta é um meio de transporte bastante comum. O reduzido contingente de sujeitos e apenas um cenário impedem a generalização dos resultados. É preciso replicar o estudo em população de trabalhadores representativas do universo, a fim de reforçar e respaldar medidas interventivas e preventivas a estes trabalhadores que são a base do cuidado na saúde pública brasileira.

\section{REFERÊNCIAS}

1. Gärtner FR, Nieuwenhuijsen K, van Dijk FJ, Sluiter JK. The impact of common mental disorders on the work functioning of nurses and allied health professionals: a systematic review. Int J Nurs Stud. 2010; 47(8): 1047-61.

2. Prochnow A, Magnago TSBS, Tavares JP, Beck CLC, Silva RM, Greco PBT. Perfil dos acidentes de trabalho publicados em estudos brasileiro. Saúde (Santa Maria).2011; [citado em $17 \mathrm{fev}$ 2016] 37(1): 77-90. Disponível em: https://periodicos.ufsm.br/ revistasaude/article/view/2900/2060.

3. Alamgir H, Cvitkovich Y, Yu S, Yassi A. Work-related injury among direct care occupations in British Columbia, Canada. Occup Environ Med. 2007; [citado em 17 fev 2016] 64(11):76975. Disponível em: https://www.ncbi.nlm.nih.gov/pmc/articles/ PMC2078424/pdf/769.pdf.

4. Ribeiro RP, Martins JT, Marziale MHP, Robazzi MLCC. Work-related illness in nursing: an integrative review. Rev esc enferm
USP. [Scielo-Scientific Electronic Library Online] 2012 [citado em 17 fev 2016]. 46(2):495-504. Disponível em: http://www.scielo. br/scielo.php?script=sci_arttext \&pid=S00806234201200020003 $1 \&$ lng=en\&nrm=iso\&tlng=en.

5. Silva JA, Dalmaso ASW. O agente comunitário de saúde e suas atribuições: o desafio para o processo de formação dos recursos humanos em saúde. Interface-Comunic.Saúde,Educ. 2002; [citado em 17 fev 2016] 6(10): 75-96. Disponível em: http://www.redalyc. org/articulo.oa?id=180114097007.

6. World Health Organization. Global experience of community health workers for delivery of health related millennium development goals: a systematic review, country cases studies, and recommendations for integration into national health systems. Pakistan: WHO; 2010. [citado em 8 març 2016] Disponível em: http://www.who.int/workforcealliance/knowledge/publications/ CHW_FullReport_2010.pdf?ua=1.

7. Ministério da Saúde (Br). Portal da Saúde [site de Internet]. Histórico de Cobertura de Saúde da Família. [citado em 20 set. 2016] Disponível em: http://dab.saude.gov.br/portaldab/historico_cobertura_sf.php.

8. Brasil. Lei n. 8080 de 19 de setembro de 1990. Dispõe sobre as condições para a promoção, proteção e recuperação da saúde, a organização e o funcionamento dos serviços correspondentes e dá outras providências. Diário Oficial da União, Brasília (DF) 1990 set. 20; Sec.1:18055.

9. Ministério da Saúde (Br). Gabinete do Ministro. Portaria n. 1.823, de 23 de agosto de 2012. Institui a Política Nacional de Saúde do Trabalhador. Diário Oficial da União [da República Federativa do Brasil], Brasília (DF) 2012 ago 24; Sec. 1, 165:46-51. 10. Ministério da Fazenda ( $\mathrm{Br}$ ). Anuário estatístico da previdência social-2015. Brasília; 2016.

11. Brasil. Lei n. 8213 de 24 de julho de 1991. Dispõe sobre os planos de benefícios da previdência social e dá outras providências. Diário Oficial da União, Brasília (DF), 1991 jul. 24; Sec.1: 14809. 12. Rossi DAN, Contrera-Moreno L. Riscos à saúde no trabalho do agente comunitário de saúde de Sidrolândia, MS. Ensaios e Ci. 2006; [citado em 17 fev 2016] 10(3): 191-200. Disponível em: http://www.redalyc.org/pdf/260/26012809019.pdf.

13. Brook I. Management of human and animal bite wound infection: an overview. Curr Infect Dis Rep. 2009;11(5):389-95. 14. Drebit S, Shajari S, Alamgir H, Yu S, Keen D. Occupational and environmental risk factors for falls among workers in the healthcare sector. Ergonomics. 2010; 53(4): 525-36.

15. Dias MAC, Machado AA, Santos BMO. Acidentes ocupacionais por exposição a material biológico: retrato de uma realidade. Medicina (Ribeirão Preto) 2012; [citado em 17 fev 2016] 45(1):12-22. Disponível em: http://www.revistas.usp.br/rmrp/article/view/47479/51207. 16. Julio RS, Filardi MBS, Marziale MHP. Acidentes de trabalho com material biológico ocorridos em municípios de Minas Gerais. Rev Bras Enferm. [Scielo-Scientific Electronic Library Online] 2014 [citado em 17 fev 2016]. 67(1): 119-26. Disponível em: http://www. scielo.br/pdf/reben/v67n1/0034-7167-reben-67-01-0119.pdf.

17. Ribeiro EJG, Shimizu HE. Acidentes de trabalho com trabaIhadores de enfermagem. Rev Bras Enferm. [Scielo-Scientific Electronic Library Online] 2007 [citado em $17 \mathrm{fev}$ 2016]. 60(5): 535-40. Disponível em: http://www.scielo.br/pdf/reben/v60n5/ v60n5a10.pdf.

18. Ribeiro PC, Ribeiro ACC, Lima Júnior FPB. Perfil dos acidentes de trabalho em um hospital de Teresina, PI. Cogitare enferm. 2010; [citado em 17 fev 2016] 15(1):110-6. Disponível em: http:// revistas.ufpr.br/cogitare/article/view/17181/11316.

19. Coriolano MWL, Lima LS. Grupos focais com agentes comunitários de saúde: subsídios para entendimento destes atores sociais. Rev enferm UERJ, 2010; [citado em 17 fev 2016] 18(1):92-6. Disponível em: http://www.facenf.uerj.br/v18n1/v18n1a16.pdf. 20. Trindade LL, Lautert L. Syndrome of Burnout among the workers of the Strategy of Health of the Family. Rev esc enferm 
USP. [Scielo-Scientific Electronic Library Online] 2010 [citado em 17 fev 2016]. 44(2):274-9. Disponível em: http://www.scielo.br/ pdf/reeusp/v44n2/en_05.pdf.

21. Santos IER, Vargas MM, Reis FP. Estressores laborais em agentes comunitários de saúde. Rev Psicol, Organ Trab. 2014; [citado em 17 fev 2016] 14(3):324-35. Disponível em: http://pepsic. bvsalud.org/pdf/rpot/v14n3/v14n3a08.pdf.

22. Mota CM, Dosea GS, Nunes PS. Avaliação da presença da síndrome de burnout em agentes comunitários de saúde no município de Aracaju, Sergipe, Brasil. Ciênc saúde coletiva. [Scielo-Scientific Electronic Library Online] 2014 [citado em 17 fev 2016]. 19(12):4719-26. Disponível em: http://www.scielosp.org/pdf/csc/ v19n12/1413-8123-csc-19-12-04719.pdf.

23. Barroso SM, Guerra ARP. Burnout e qualidade de vida de agentes comunitários de saúde de Caetanópolis (MG). Cad. saúde colet. [Scielo-Scientific Electronic Library Online] 2013[citado em 17 fev 2016]. 21(3): 338-45. Disponível em: http://www.scielo.br/ pdf/cadsc/v21n3/v21n3a16.pdf.

24. Oliveira AC, Gonçalves JA. Occupational accident with sharpe edge material among workers of an operating center. Rev esc enferm USP. [Scielo-Scientific Electronic Library Online] 2010 [citado em 31 mar 2016]. 44(2):482-7. Disponível em: http://www.scielo. br/pdf/reeusp/v44n2/en_34.pdf.

25. Theodoro ED, Miotto MHMB, Barcellos LA, Grillo CHB. Prevalência dos acidentes de trabalho em cirurgiões-dentistas. Rev Bras Pesquisa em Saúde. 2009; [citado em 31 mar 2016] 11(4):4-9. Disponível em: http://periodicos.ufes.br/RBPS/article/view/348/259.
26. Leite PC, Silva A, Merighi MAB. A mulher trabalhadora de enfermagem e os distúrbios osteomusculares relacionados ao trabalho. Rev esc enferm USP. [Scielo-Scientific Electronic Library Online] 2007 [citado em 31 mar 2016]. 41 (2): 287-91. Disponível em: http://www.scielo.br/pdf/reeusp/v41n2/15.pdf.

27. Nascimento GM, David HMSL. Avaliação de riscos no trabalho dos agentes comunitários de saúde: um processo participativo. Rev enferm UERJ. 2008; [citado em 17 fev 2016] 16(4): 550-6. Disponível em: http://www.facenf.uerj.br/v16n4/v16n4a16.pdf. 28. Bacchieri G, Gigante DP, Assunção MC. Determinantes e padrões de utilização da bicicleta e acidentes de trânsito sofridos por ciclistas trabalhadores da cidade de Pelotas, Rio Grande do Sul, Brasil. Cad Saúde Pública. [Scielo-Scientific Electronic Library Online] 2005 [citado em 31 mar 2016]. 21(5):1499-508. Disponível em: http://www.scielo.br/pdf/csp/v21n5/23.pdf.

29. Persaud N, Coleman E, Zwolakowski D, Lauwers B, Cass D. Nonuse of bicycle helmets and risk of fatal head injury: a proportional mortality, case-control study. CMAJ. 2012; [citado em 31 mar 2016] 184(17):E921-3. Disponível em: http://www.cmaj.ca/ content/184/17/E921.long.

30. Oliveira EA, Manosso RM, Braune G, Marcenovicz PC, Kuritza LN, Ventura HLB et al. Neighborhood and postal worker characteristics associated with dog bites in postal workers of the Brazilian National Postal Service in Curitiba. Ciên saúde coletiva. [Scielo-Scientific Electronic Library Online] 2013 [citado em 31 mar 2016]. 18(5): 1367-74. Disponível em: http://www.scielo. $\mathrm{br} / \mathrm{pdf} / \mathrm{csc} / \mathrm{v} 18 \mathrm{n} 5 / 22 . \mathrm{pdf}$. 